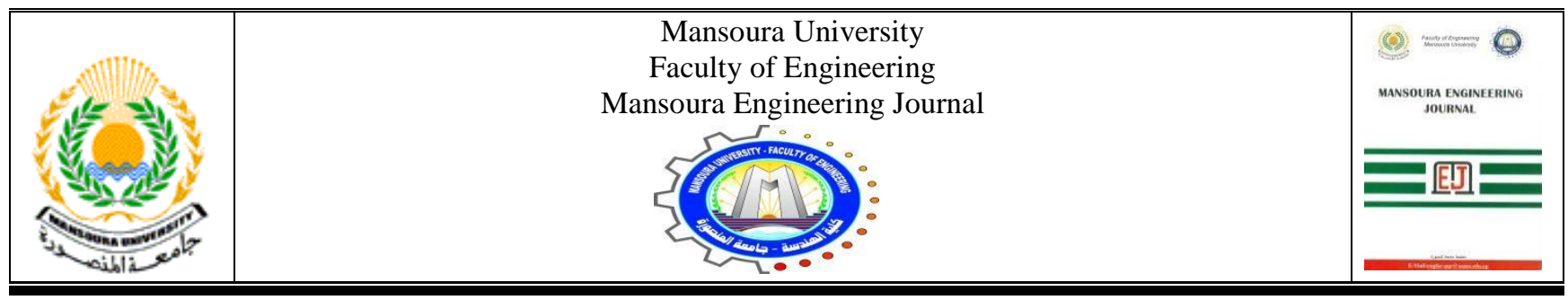

\title{
Control the ambient noise level to increase the acoustic efficiency of the educational building

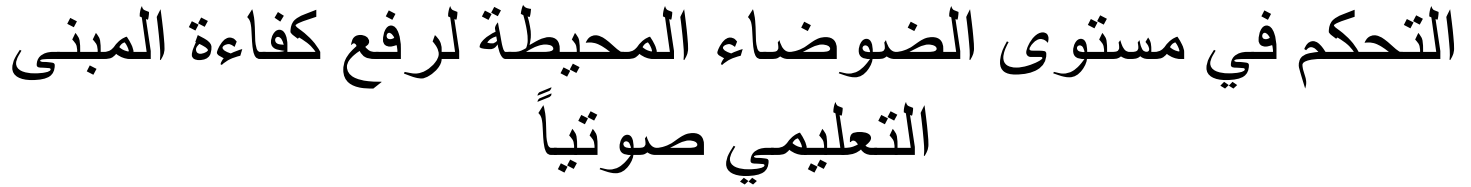

\author{
SanaaAbd-Elghany El-Dyasty Ahmed Eid, Alaa Mohammed Shams El-Deen El-Eashy and Asmaa \\ Nasr EldinElbadrawy
}

\begin{abstract}
KEYWORDS:
Acoustics, Performance, educational building, sound level meter, decibel, classroom.
\end{abstract}

Abstract:-This research deals with improving the acoustic performance of educational buildings and take it into account through primary design stages, (case study of the Faculty of Engineering, Mansoura University) and study the sound performance and different ways of noise control in order to come up with solutions that improve the educational efficiency of the building and improve the educational process .

The study at hands considers the following:

- Noise control methods on the building:

- Environmental noise rates and standards in codes:

-Sound needs of spaces and noise resulting from them.

-Maximum ambient noise levels.

- Required sound insulation values between the spaces of the educational building.

- The measuring device used.

- Study area: - The main block halls surrounding the main entrance.

- Proposals to improve the sound performance of the study part of the college
على الوضع الراهن للمبنى ومقارنه النتائج بمعايير الضوضاء البيئية في الاكواد بهدف

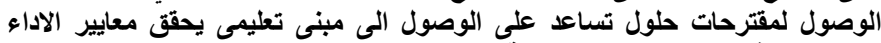

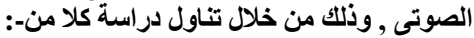

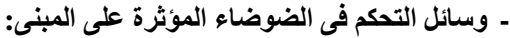

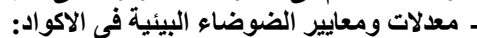

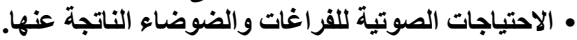

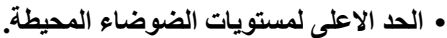

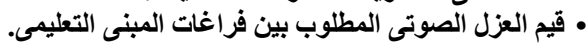

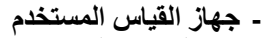
ـ منطقة الاراسة: ـ ـ قاعاعات البلوكات الرئيسية المحيطة بالمدخل الرئئيسي. ـ مقترحات لتحسين الاداء الصوتى لجزء البات الدراسة بالكلية .

$$
\text { I }
$$

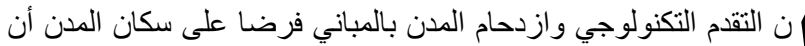

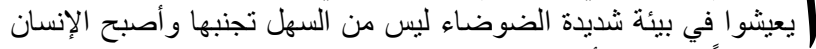

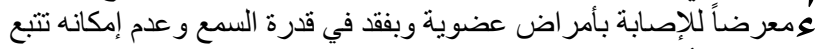

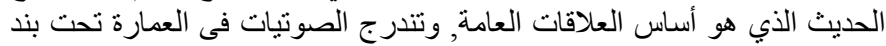

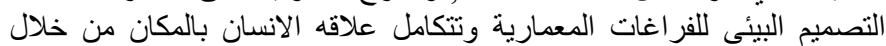

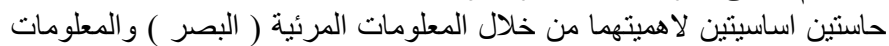

ملخص البحث :-تهذف الاراسة بصورة رئيسية الى التعرف على أوجه القصور

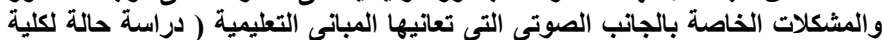

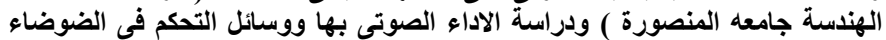
المؤثرة بهاءف الخروج بتوجهات حلول تعمل على رفع كفاءة المبنى التعليمى صوتيا والارتقاء بالعملية التعليمية.

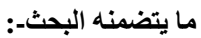

تناول البحث منهج الوصفى التحليلي للحالة من خلال جمع المعلومات اللازمة والتى التى التئي

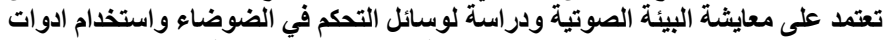

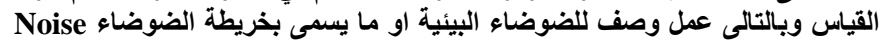
وتحديد اماكن الضوضاء بالموقع والتى تمثل مصادر ضوضاء لخداء مرتفعه للتعرف

Received: (12 July, 2017) - Accepted: (13 December, 2017)

Sanaa Abd El-ghany El-dyasty Ahmed, Demonstrator, Dep of Architectural Engineering, Faculty of Engineering Mansoura University (email: sanaaaeldyasty@gmail.com)

Alaa Mohammed Shams El-Deen El-Eashy, Associated Professor in Architecture- Dep, Faculty of Engineering, Mansoura University (e-mail: arabeskal_arch@yahoo.com)

Asmaa Nasr EldinElbadrawy, Lecturer, Architecture- Dep, Mansoura University(e-mail: a_n_elbadrawy@yahoo.com.au) . 


\begin{tabular}{|c|c|}
\hline معيار الضوضاء بالايسيبل & نوع الفراغ \\
\hline 25 & قاعة محاضر ات \\
\hline $20-30$ & مكتب إدارى \\
\hline $30-25$ & قاعة مؤتمر ات \\
\hline $35-25$ & قاعة إجتماعات \\
\hline $30-35$ & مكتب- مكتبة \\
\hline
\end{tabular}

\begin{tabular}{|c|c|c|}
\hline المكافوب الصوت dB & الددى الدفضل لقيمة & نوع الفراغ والمواصفات الصوتية \\
\hline $\begin{array}{l}38: 30 \\
\end{array}$ & 30:20 & 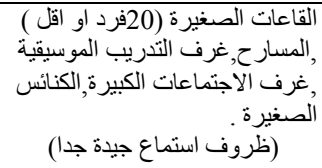 \\
\hline $42: 38$ & $35: 30$ & 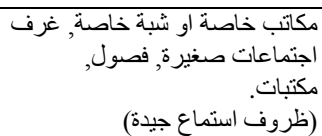 \\
\hline $52: 47$ & 45:40 & 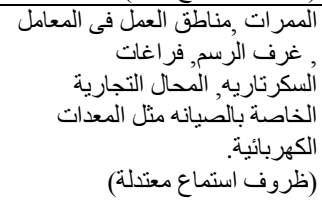 \\
\hline
\end{tabular}

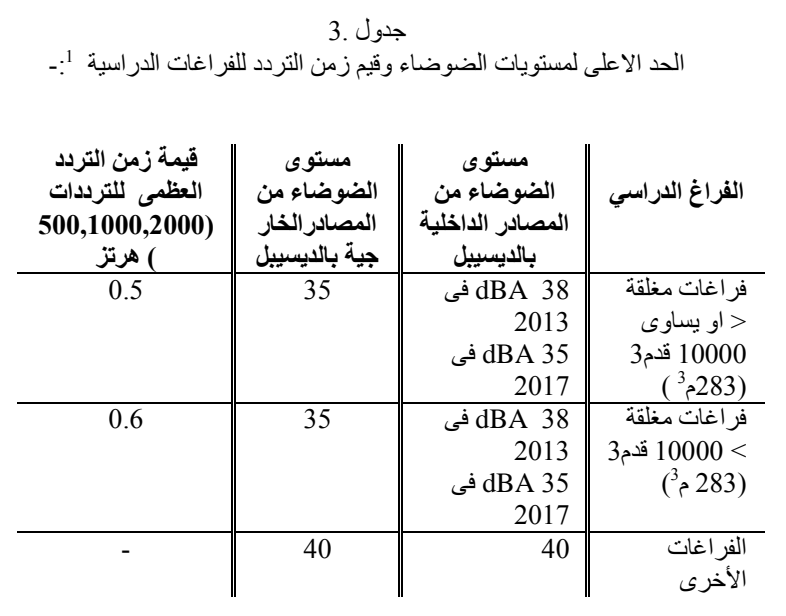

2. بعد الفراغ عن الدصدر :-ويعتبر اول اسلوب للمعالجه الصوتية وذللك باختيار مكان المنشأة التعليمية

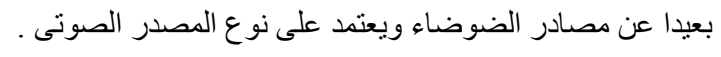

الغير مرئية ( المعلومات السمعية والثمية ), ولذلك يعتبر الاداء الصوتي احد

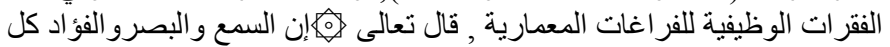

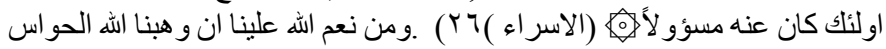

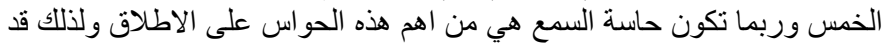

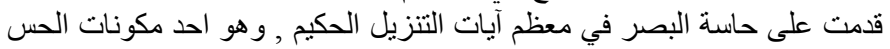

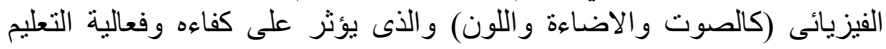
وسهولة الاتصال بين المعلم والطالب وبالتالى الراحة الفيزيائية للطالب ودافئي وافعيته للتعلم.

\section{وسائل التحم فى الضوضاء المؤثرة علي المبنى التعليمى :- II}

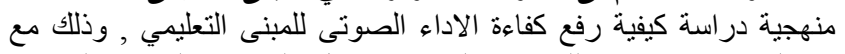

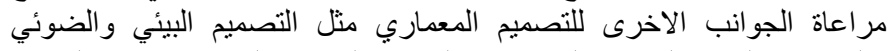

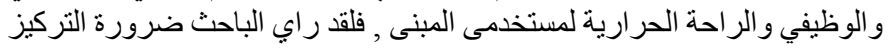

$$
\text { علي وسائل التحكم في الضوارية لمساء من خلال تتاول در اسة كلا من :- }
$$

1. مخطط

وسائل التحكم في الضوضاء للوصول لمعايير تصميمية وتخطيطية :

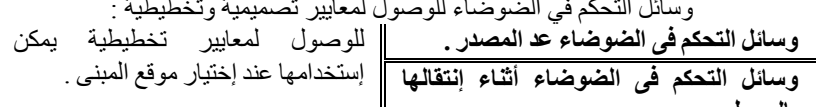

\begin{tabular}{|c|c|}
\hline & بالوسط. \\
\hline 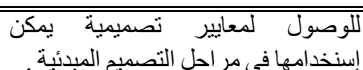 & وسائل التحكم فى الضوضاء عد المستقبل. \\
\hline
\end{tabular}

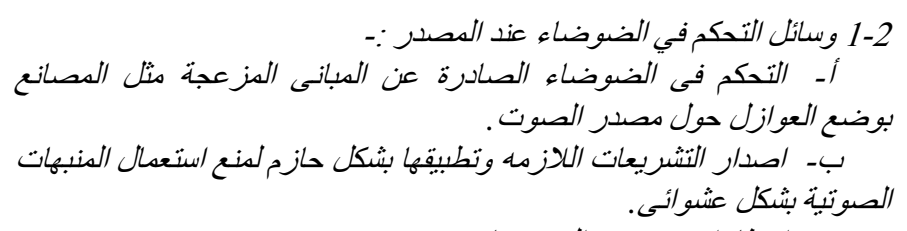

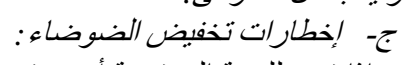

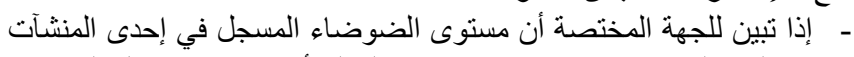

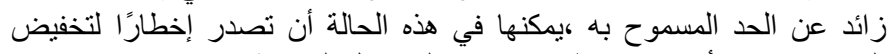

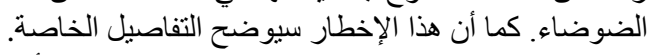

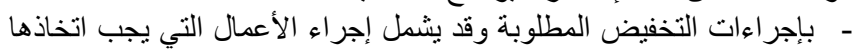

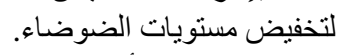
- - من المتوقع أن تكون إخطار ات التخفيض بناءعلى كلى كل من التقييمات المادية

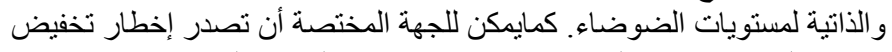

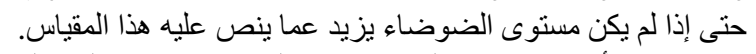

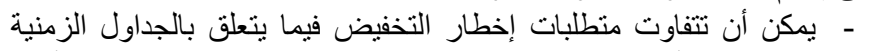

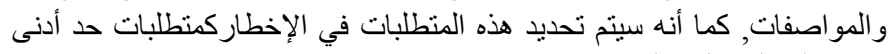
يجب على المشغل الالتز ام تماما بها.

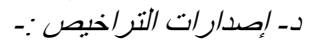

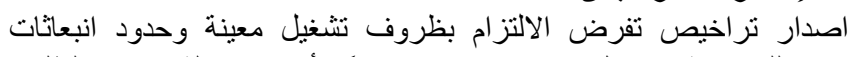

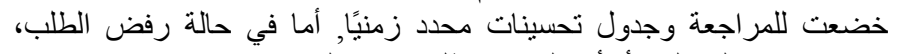

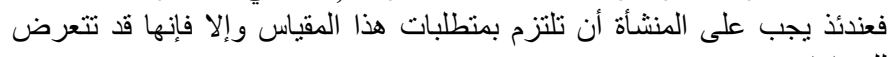

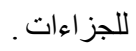

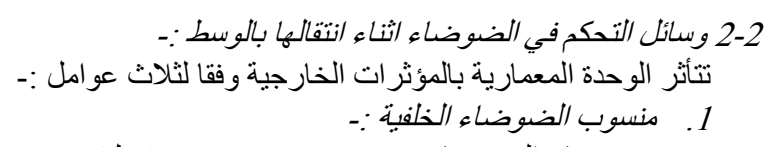

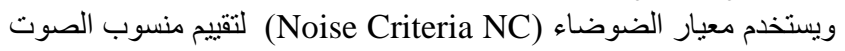

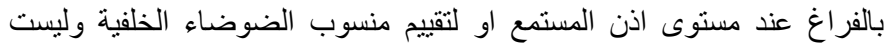

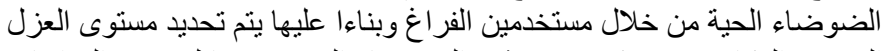

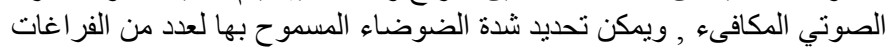

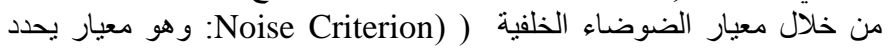
الحد الاقصى المسموح به للضوضاء لكول لكل فر اغ مختلف . 
وتؤثر الدواجز الصوتية علي الضوضاء من خلال معامل فقدان الانتقال

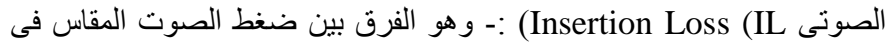

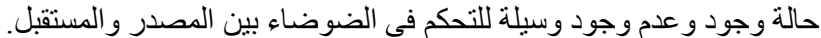

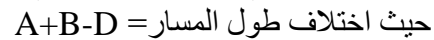

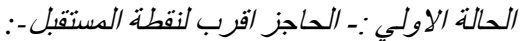

اختلاف طول المسار = A+B-D : A فقد الانتقال للحاجز عند تردد 1000 هرتز = 19

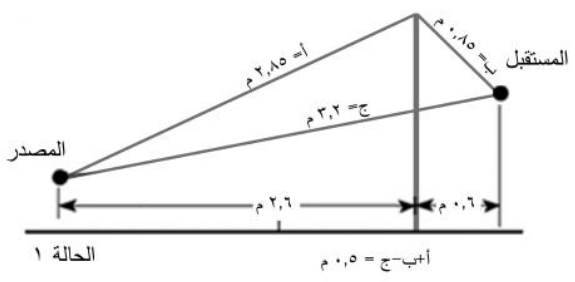

شكل. 3. الحاجز اقرب لنقطة المستقبل 4

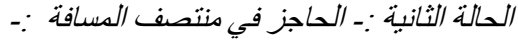
اختلاف طول المسار = A+B-D = 3.2-1.6+2 = 0.4 فقد الانتقال للحاجز عند تردد 1000 هرنز = 18

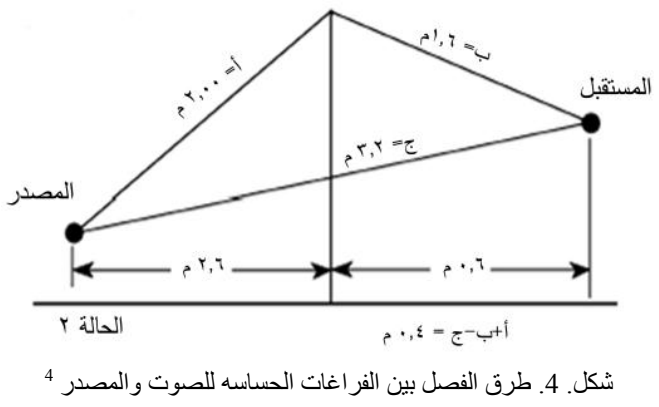

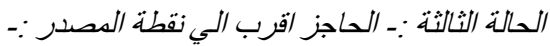

اختلاف طول المسار = 2.

فقد الانتقال للحاجز عند تردد 1000 هرتز = 21 ت

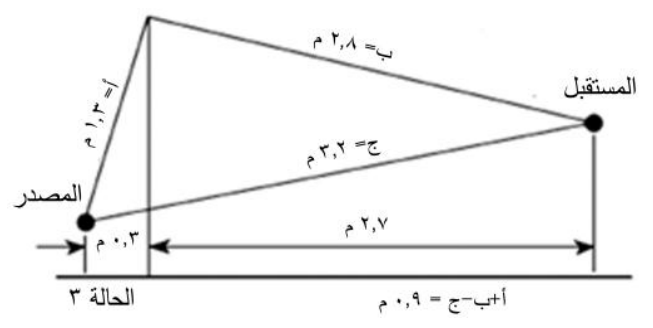

شكل. 5. الحاجز اقرب لنقطة المصدر 4

يتضح ان افضل حالة هى ان يكون الحاجز اقرب لنقطة الدصدر واسوء حاله ان يكون الحاجز فى منتصف المسافة .

3-2 وسائل التحكم في الضوضاء عند المستقبل :

وتهلف الانظمة الصوتية الى خلق بيئة معيشية او وظيفية مريحة الطية وخالية من

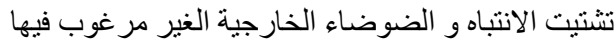
و هناك ثلاث طرق للتحكم فى نفاذ الضوضاء للفئ للفر اغ للوصول اللى البيئة الصوتية

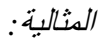

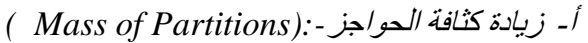
و هى عبارة عن زيادة كثافة الكتلة للحوائط او العناصر الانثائية الاخرى

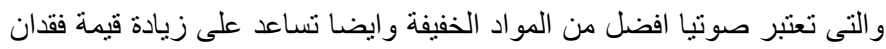

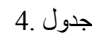

تصنيف الاصو ات ومعايير بعد المدرسة عن موقع هذه الاصوات 9.

\begin{tabular}{|c|c|c|c|c|c|}
\hline الامثلة & الضل الضين & المتيةتبة & مستوى شده & تصنيف & م \\
\hline 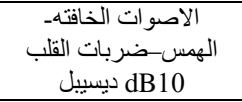 & - & مقبول & $10-0$ & مسموع & 1 \\
\hline حفيف الورق 20 ديسييل & - & مقبول & $30-10$ & هادىء & 2 \\
\hline حركة المرور الخفيفة 40 ديسيل - 50 ديسيل & - & مقبول & $50-30$ & هادىء & 3 \\
\hline الامثلة & الضمل مسافة & المترتبة & ( الصوت شدن ) & تصنيفت & a \\
\hline 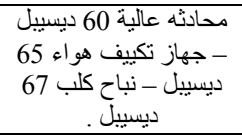 & 10 & مضايقة & $70-50$ & متوسطاع & 4 \\
\hline 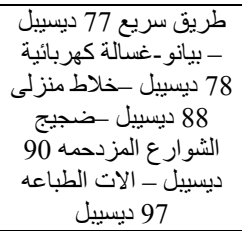 & 320 & ضالسمع جدا & $100-70$ & مرتفع & 5 \\
\hline 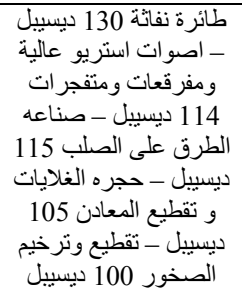 & 1000 م & يؤدى الصى & $\begin{array}{r}-100 \\
130\end{array}$ & مزعج & 6 \\
\hline
\end{tabular}

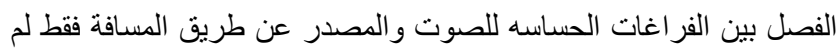
يعد كافيا خاصة فى المدن الصاخبة ويمكن تجنبها بواسطة حواجز لإنز من عناصر

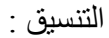

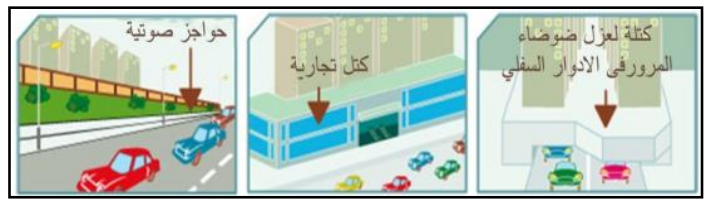

شكل. 1. طرق الفصل بين الفر اغات الحساسه للصوت و المصدر 6

3- اضافة الحو/جز الصوتبة :--

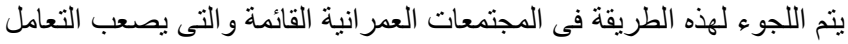
معها عن طريق الاجر اءات المعمارية.

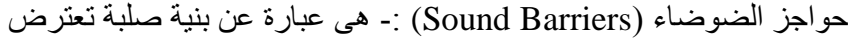
مسار الصوت المباثر وتقلل من مستوى ضغط الصوت داخل منطقة الظل .

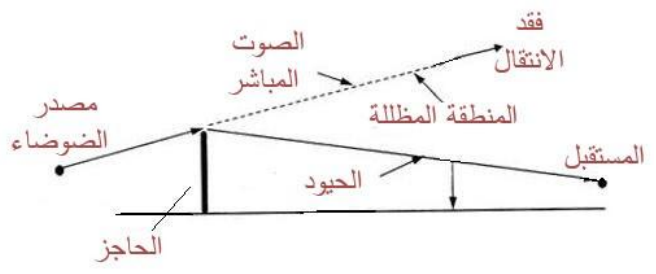

شكل. 2. تعامل الموجات الصوتية مع الحواجز 5 


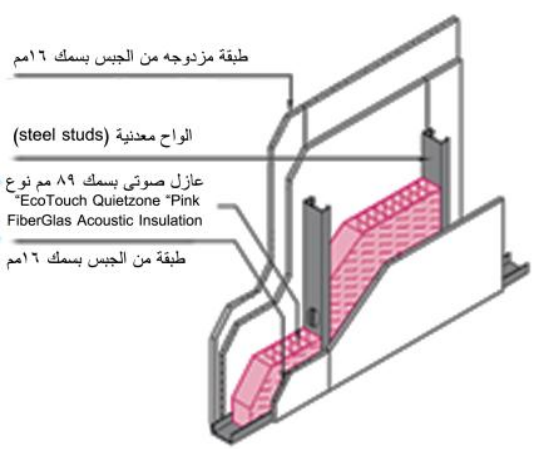

شكل. 8. زيادة قيمة STL باضافة تجويف بمادة ماصة

$$
\text { للصوت } 4
$$

معدلات ومعايير الضوضاء البيئية فى الاكواد : III

أ- الاحتباجات الصوتية للفراغات والضوضلاء الناتجة عنها :

$$
\text { 5. جدول }
$$

\begin{tabular}{|c|c|}
\hline ( غرف المعيدين- المكتبة ) . & 1ـ فراغات هادئة تحتاج الى هدوء. \\
\hline ( المسجد ــ القاعات الدر اسية ) & 2- فراغات ينتج عنها ضوضاء متوسطة \\
\hline 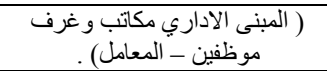 & احتياجا للهاتو ينتج عنها ضوضاء متوسطة و أقلّ \\
\hline 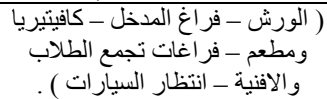 & 4ل لهـواء . فرات مزعجة صوتيا وأقل احتياجا \\
\hline 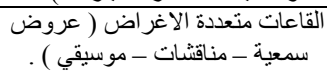 & 5- فراغات مزعجه صوتيا وتحتاج الى هلوء . \\
\hline 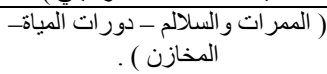 & 6تاج الى هدوء ينتج عنها ضوضاء متوسطة ولا \\
\hline
\end{tabular}

مجمو عات الفراغات تبعا لاحتياجاتها الصوتية والضوضاء الناتجة عنها :- الصنات

ب- قبم العزل الصوتى المطلوب بين فراغات المبنى التعليهى :-

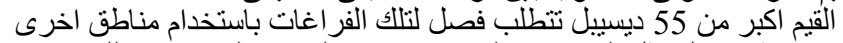

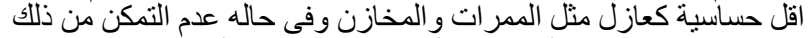

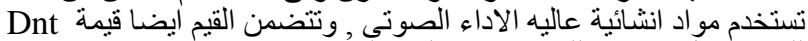
للحائط ككل بما فى ذلئ الابو ابه والاب والثبابيك .

$$
\text { القيم الدنيا المطلوبة للعزل الصونى بين الفراغات } 11 \text { :- }
$$

قيمة العزل الصوتى للصوت الصوت

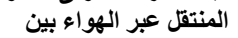

$\mathbf{D}_{\mathrm{nT}}\left(\mathbf{T}_{\mathrm{mf}, \mathrm{max}}\right), \mathrm{w}$ الفراغات

\begin{tabular}{|c|c|c|c|c|c|}
\hline \multirow{5}{*}{ الضى الغرضفة } & & منذفض & متوسط & مرتفع & جرتفع \\
\hline & مرتفع & 30 & 35 & 45 & 55 \\
\hline & متوسط & 35 & 40 & 50 & 55 \\
\hline & منخفض & 40 & 45 & 55 & 55 \\
\hline & منذا & 45 & 50 & 55 & 60 \\
\hline
\end{tabular}

$$
\text { الضوضاء الناتجة عن غرفة المصدر }
$$

(dB)
انتقال الصوت ( Sound transmission loss - STL ) , وكقاعدة عامة فان كل مضاعفة فى وزن الحائط يزيد قيمة STL كائل

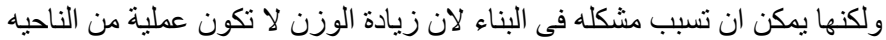

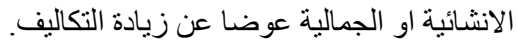

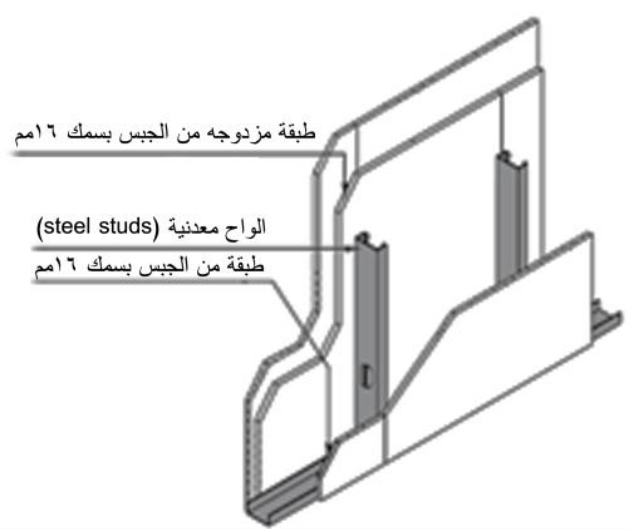

${ }^{4}$ STL شكل. 6. اضافة طبقة اخرى من الواح الجبس لزيادة قيمة

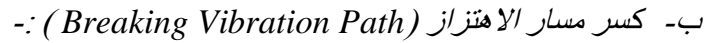

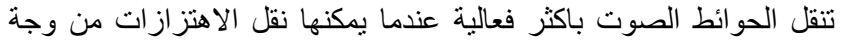

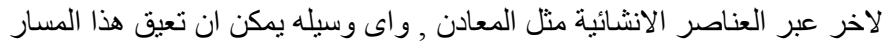

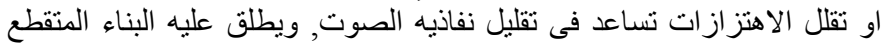

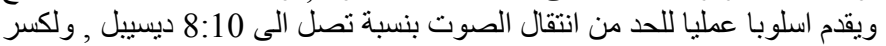

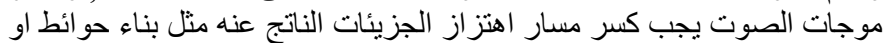

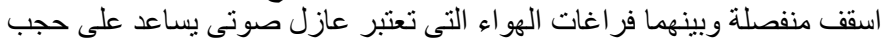

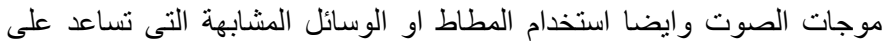
قطع مسار الموجات . موت الموت

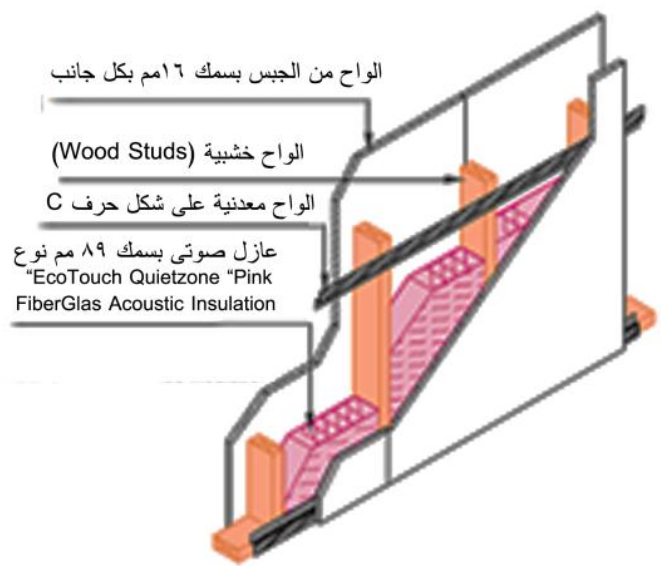

شكل. 7. اضافة عاصر تقلل من قيمة STL

ج- توفيرتجويف الامتصاص ( Providing Cavity absorption ):-

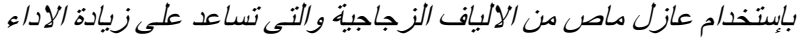

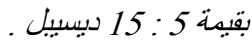




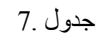

قيم العزل الصوتى بين الفر اغات طبقا لشكل .10 :-

\begin{tabular}{|c|c|}
\hline مدى قيمة العزل الصوتى المطلوبة بالايسييل & 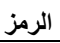 \\
\hline$(40: 35)$ & $*$ \\
\hline$(45: 40)$ & ** \\
\hline$(50: 45)$ & $* *$ \\
\hline$(55: 50)$ & $* *$ \\
\hline$(60 \cdot 55)$ & $* * *$ \\
\hline & $* *$ \\
\hline 60 ديسييل ( ويفضل زيادة المسافات الفاصلة بين هذ. & $* * *$ \\
\hline
\end{tabular}

(مدى احتيّاج الفراغ لللهنوء) (مئ)

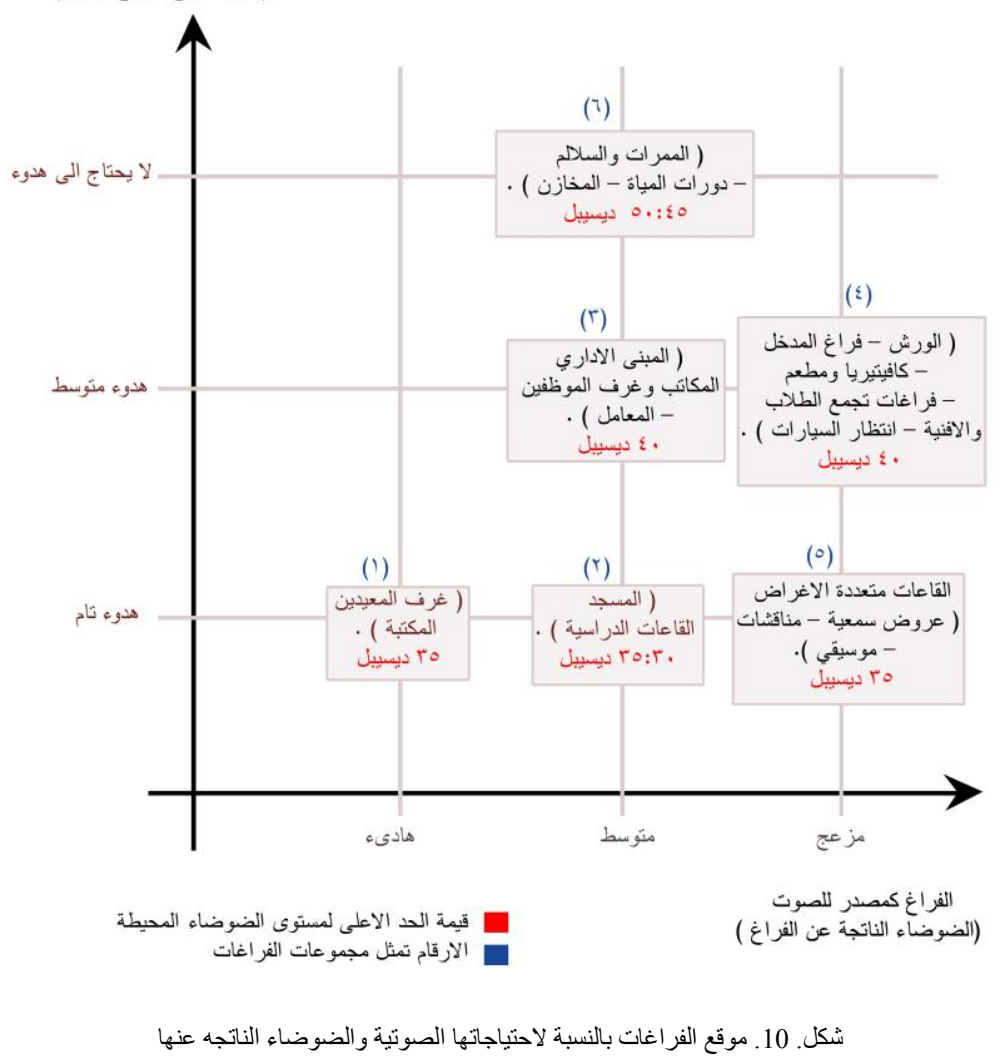

جهاز القياس المستخدم :- IV

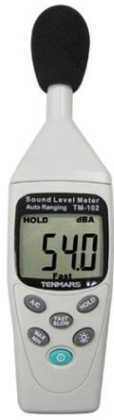

(sound شكل. 11. جهاز قياس مستوى شدة الصوت Level Meter Auto)

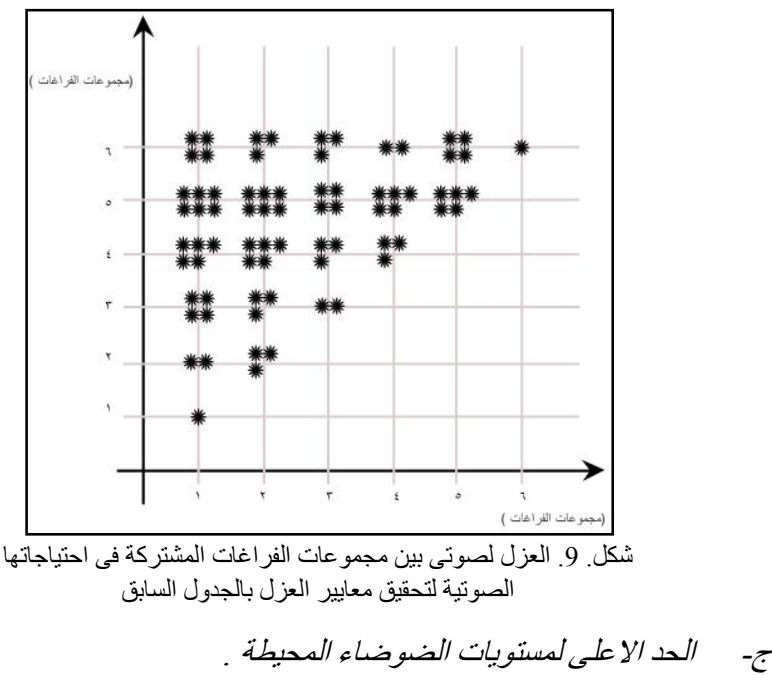

\section{ج}




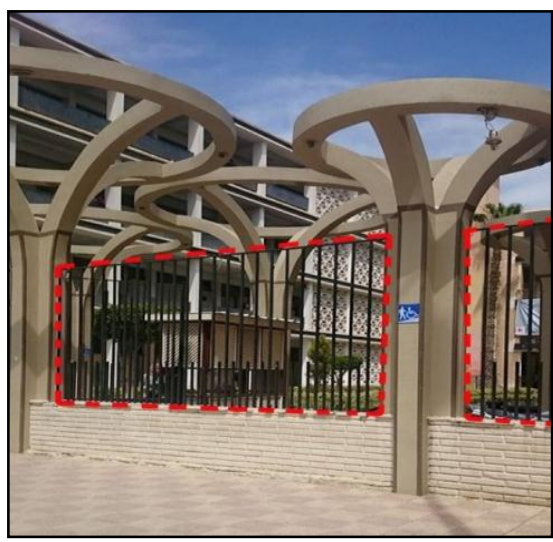

شكل. 14. الحاجز بين فراغ المذخل وشارع المرور الامامى

ج-العلاقة بين الفراغات الدر/سية والانشطة المحبطة :-

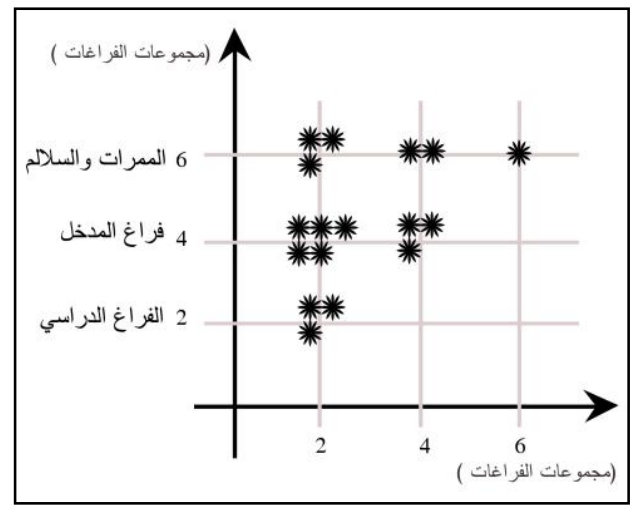

شكل. 15. قيم العزل المطلوبة بين مجمو عات الفراغات المحيطة بفر اغ المدخل الرئيسي

$$
\text { د- التقبيم الصوتسى للبولك :- }
$$

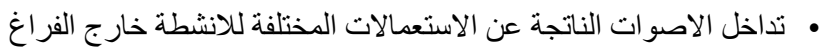

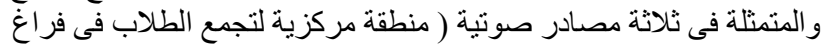

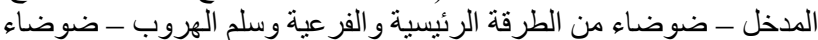

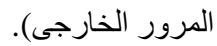

• عدم الحفاظ على الخصوصية الوظيفية المتمثلة فى مسار الدخول المخترق

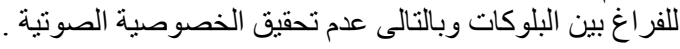
ه- بلوك 3 (اتصالات) :

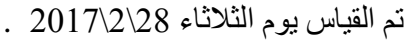

8.

قيم مستويات شدة الضوضاء(-Lmin50-L10-L1Lmax-L) لقاعة 8212B بيلوك اتصالات

\begin{tabular}{c||c||c||c||c||c}
$\begin{array}{c}\mathbf{L} \\
\mathbf{m i n}\end{array}$ & L 50 & L 10 & L 1 & L max & الزمي \\
\hline 48 & 57 & 64 & 67 & 74 & $\mathbf{8}$ \\
\hline 43.6 & 63 & 66 & 72 & 73 & $\mathbf{9}$ \\
\hline 56 & 60 & 64 & 69 & 72.5 & $\mathbf{1 0}$ \\
\hline 44 & 62 & 66 & 72 & 73 & $\mathbf{1 1}$ \\
\hline 56.7 & 61 & 63 & 64 & 66 & $\mathbf{1 2}$ \\
\hline 57 & 60 & 64 & 72 & 72 & $\mathbf{1 3}$ \\
\hline 56.5 & 58 & 60.5 & 62 & 63 & $\mathbf{1 4}$ \\
\hline 57 & 60 & 62 & 64 & 68 & 15
\end{tabular}

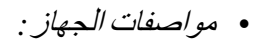

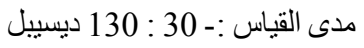

( منخفضه من 30 : 80 : 80 ديسييل - منوسطة من 50 ديليل : 50 : 100 ديسييل - مرتفعة

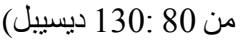

مستوى الدقة : +130:- دينيل) 1.5 ديسيبل

نطاق التردد: 30 هرتز إلي 8 كيلو هرتز

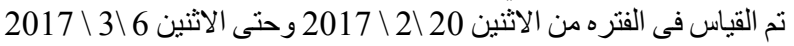

$$
\text { وذللك ايام الاثثين و الثناثثاء و الاربعاء. }
$$

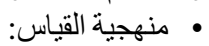

مده القياس يتر اوح من 15:10 دقيقة فى الفر اغ الو احد كل ساعه فى فترة الدوام

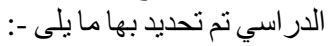

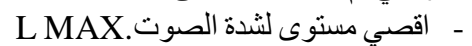

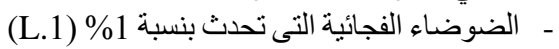

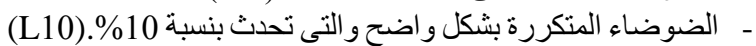

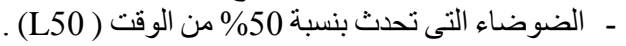

- اقل مستوى لثدة الضوضاء (L MIN) -

منطقة الاراسة :- ق قاعات البلوكات المحيطة بالمدخل الرئيسي :- V

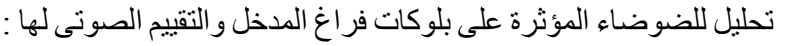

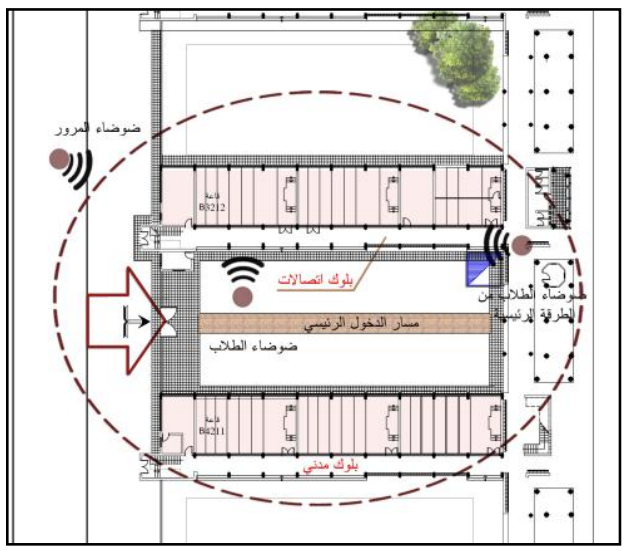

شكل. 12. بلوك 3 و4 والضوضاء المحيطة المؤثرة عليها

$$
\text { أـ مصادر الضوضاء المحبطة بالبلوكات : }
$$

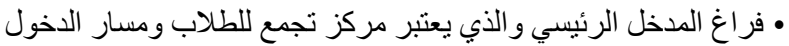
الرئيسي مخترقا الفراغ بين البلوكات.

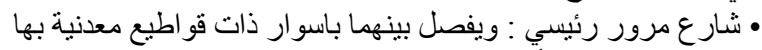

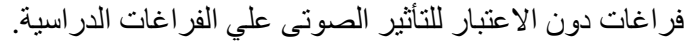

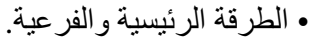

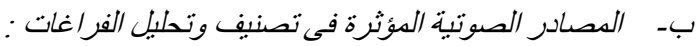

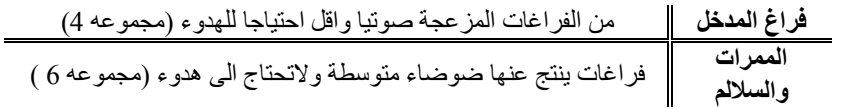

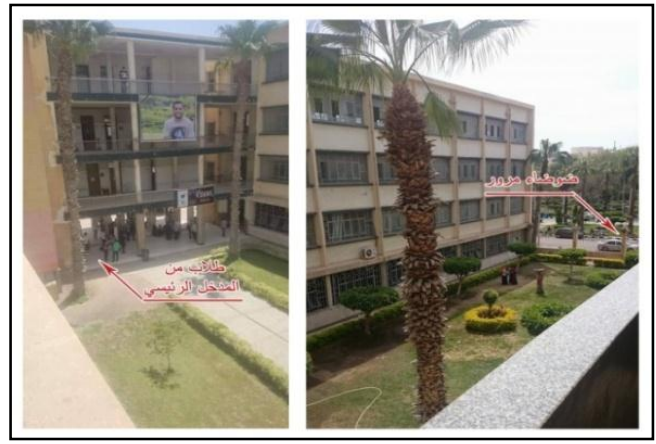

شكل. 13. المصادر الصوتية المحيطة المؤثرة على بلوك (3,4) 


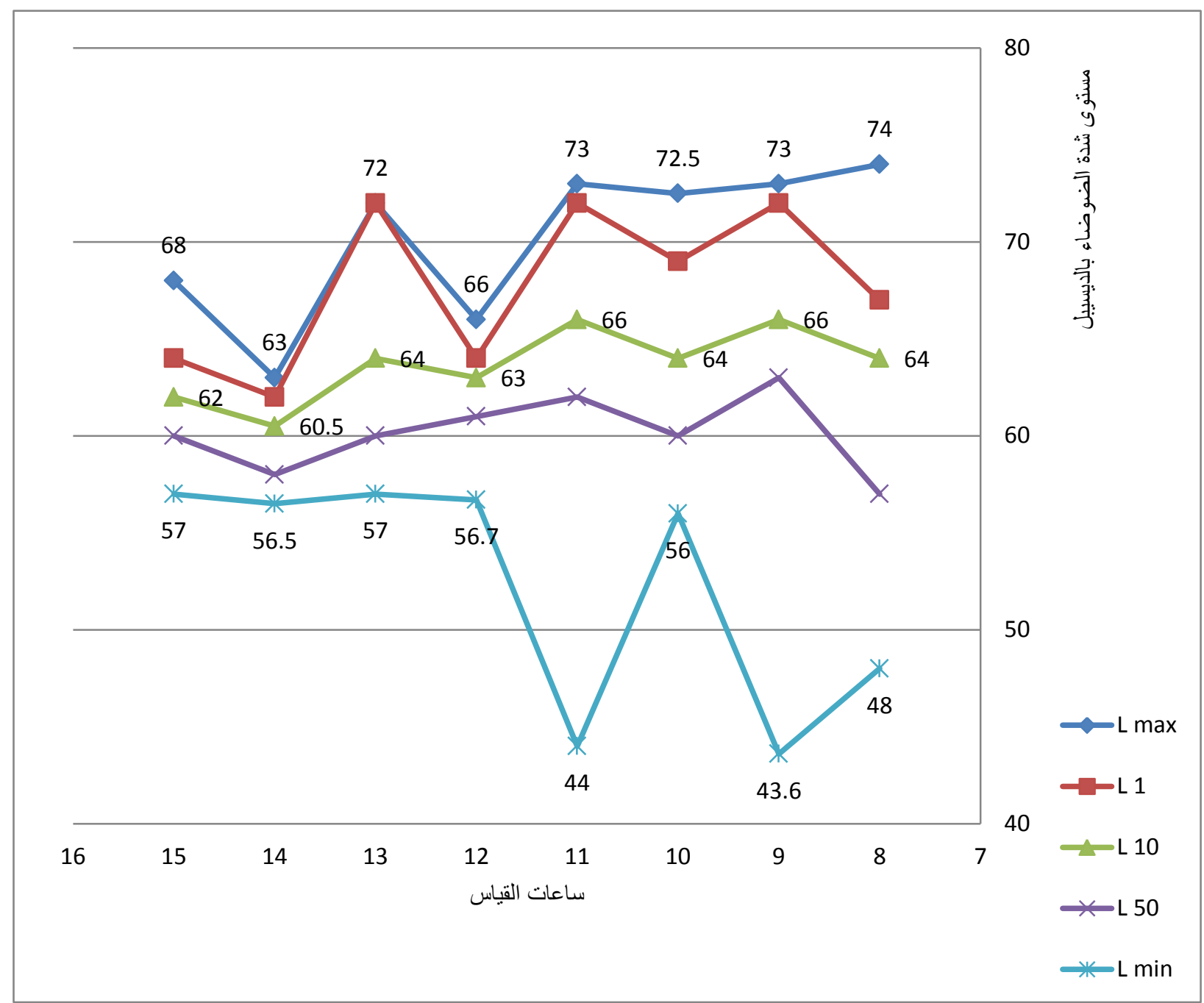

شكل. 16. مستوى شدة الضوضاء بالديسيل بقاعة 3212B مع الزمن بالساعات اثناء فترة الدوام الدراسي

9. جدول

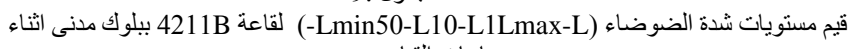

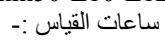

\begin{tabular}{c||c||c||c||c||c}
\multicolumn{1}{c||}{$\mathbf{L}$ min } & L 50 & L 10 & L 1 & L max & نزم) \\
\hline 55.3 & 59 & 65 & 82 & 85 & $\mathbf{8}$ \\
\hline 48 & 57 & 61 & 67 & 70 & $\mathbf{9}$ \\
\hline 62 & 66 & 68 & 69 & 71 & $\mathbf{1 0}$ \\
\hline 57.5 & 63 & 70 & 73 & 73 & $\mathbf{1 1}$ \\
\hline 59 & 64 & 68 & 70 & 74 & $\mathbf{1 2}$ \\
\hline 57 & 58 & 65 & 72 & 75.5 & $\mathbf{1 3}$ \\
\hline 57.5 & 60 & 66 & 76 & 76 & $\mathbf{1 4}$ \\
\hline 57 & 60 & 65 & 67 & 70 & 15
\end{tabular}

الملاحظات من القباس :--

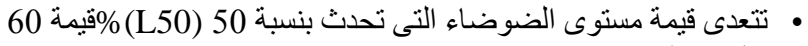

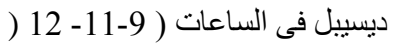

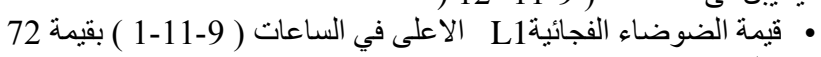

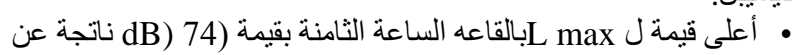

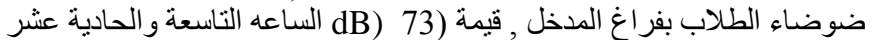

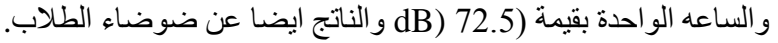

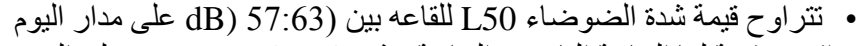
و اقصي قيمة لها الساعة التاسعه و الحادية عشر بقيمه (62-63 عل علي الترثيب

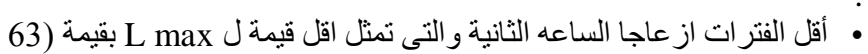

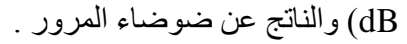




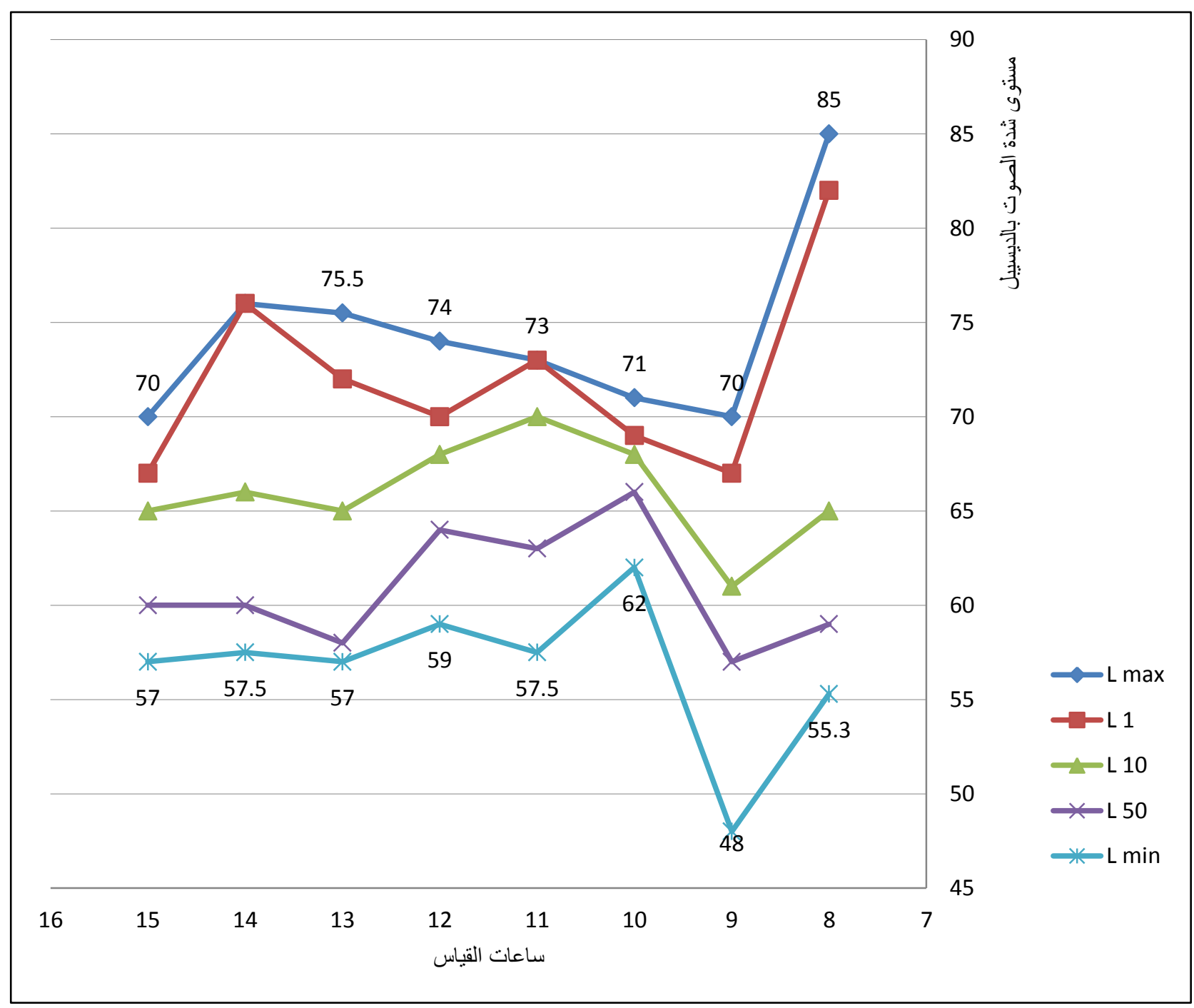

شكل. 17. مستوى شدة الضوضاء بالليسييل لقاعة 4211B ببلوك مدنى مع الزمن بالساعات اثناء فترة القياس

أـ اصدار نشريعات وتطبيقها بشكل حازم لمنع استعمال المنبهات الصوتية بشكل

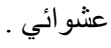

بـ استخد/م مواد الامتصاص للصوت فى الطرق لتقليل مستوى الضوضاء :

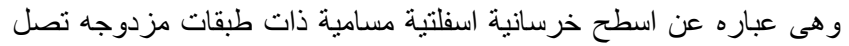

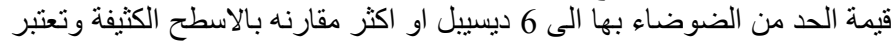

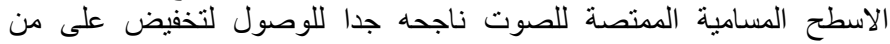

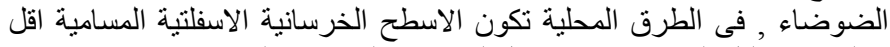

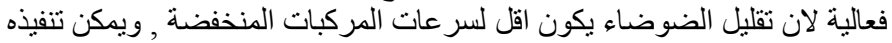
بالثار ع الفاصل بين كلية طب بيطرى لفون ومبنى الكلية.

ج- /ستخد/م الحو/جز الصوتية والنباتات ( Sound Barrier ) :-

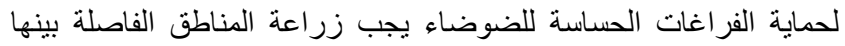

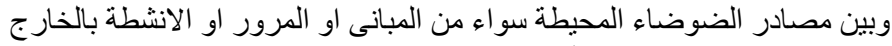

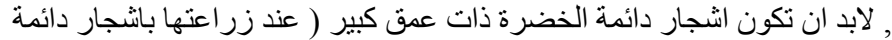

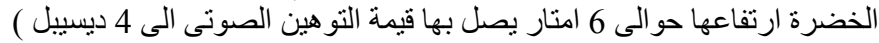

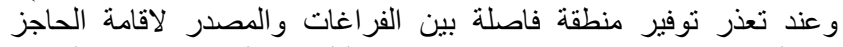

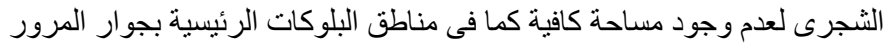

التقييم الصوتى لقاعات للبلوك :-

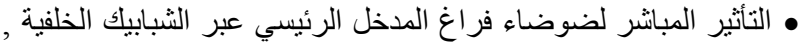

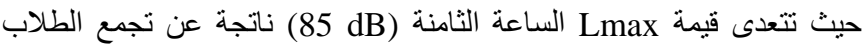

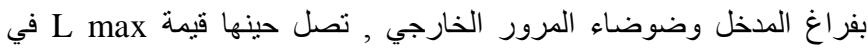

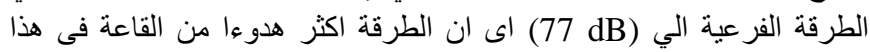
التوقيت.

• تتر اوح قيمة L50 للقاعة بين (57:66 dB) حيث اعلى قيمة لها ناتجة

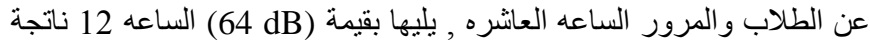
عن ضوضاء مستمر للطلاب من الطرقة الفرعية . 1.ققترحات لتحسين الاداء الصوتى لجزء الدراسة بالكلبة :• مقترحات على المستوى التخطبطي :-

وتهتم بتقليل مصادر الضوضاء المحيطة الناتجة عن سوء التخطيط الصوتى : الصوي و التحكم فى الضوضاء عند المصدر عن طريق : 
• التحكم في مسطح الفتحات و علاقتها بمصدر الضوضاء . • استخدام كاسرات وحواجز صوتية بالو اجهات .

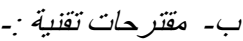

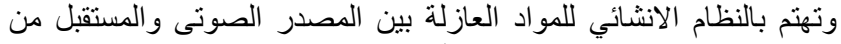

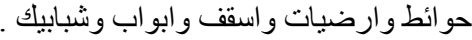
• استخد/م مواد انشاء عازلة للضوضاء :

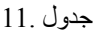
مصادر الضوضاء المحيطة بالقاعات ومستويات قياسها بالديسييل
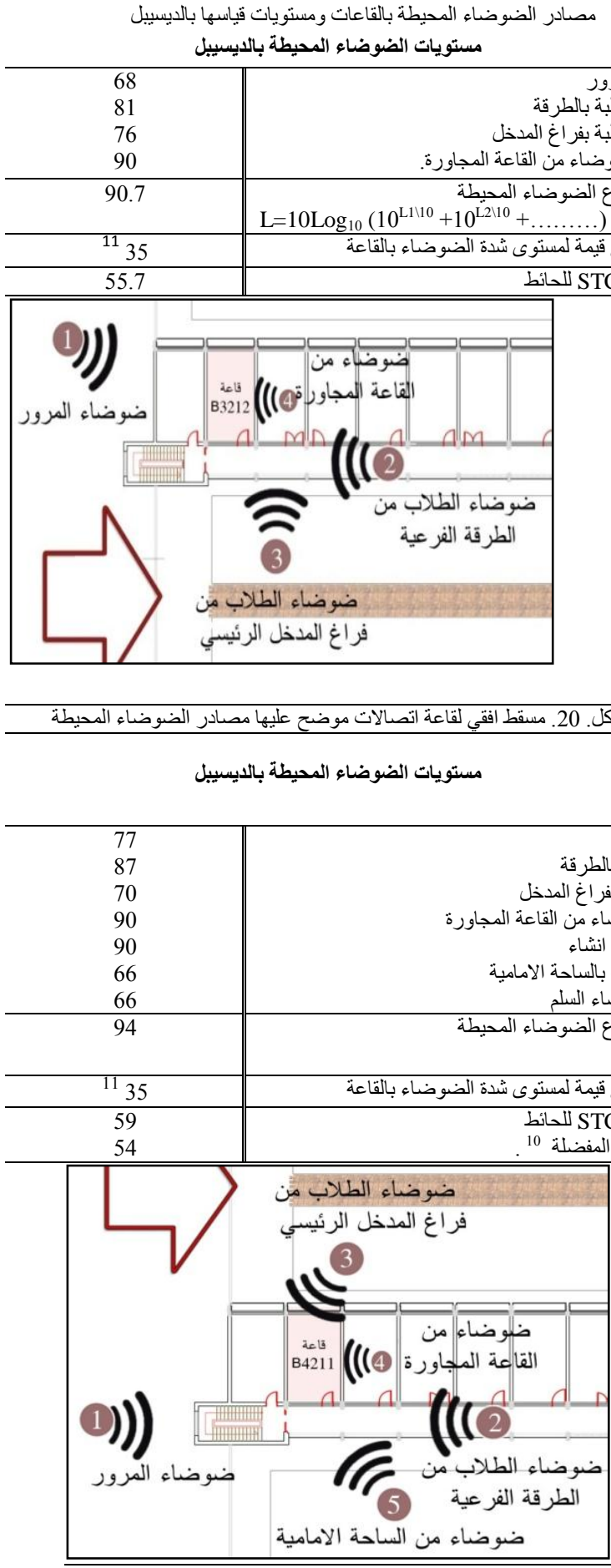

شُكل. 21. مسقط افقي لقاعة مدنى موضح عليها مصادر الضوضاء المحيطة
الخارجية (الثارع الغربي ) نلجأ لاقامة حواجز صوتية من خلال اضافة بنية

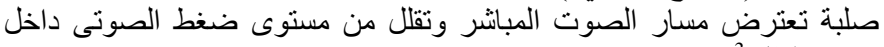
منطقة الظل 3

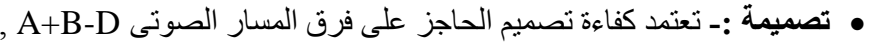

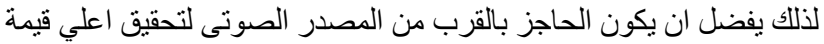
لفرق المسار وبالتالي قيمة اعلي للتو هين الصونى 2.

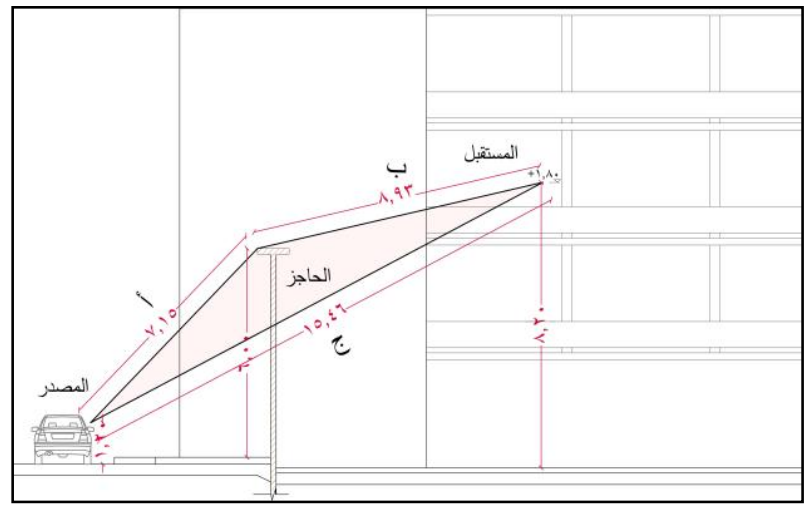
القاعة المصدر للمستقبل

10. جدول

الابعاد التصميمية للمسار الصوتى لضوضاء المرور حول الحاجز وقيمة فقد انتقال الصوت من خلاله

\begin{tabular}{|c|c|}
\hline 15.46 & المسافة بين المصدر وبالمستقبل (ج ) \\
\hline 8.93 & المسافة بين الحاجز والمستقبل (ب) \\
\hline 7.15 & المسافة بين المصدر والحاجز (أ) \\
\hline 8.20 & إرتفاع المستقبل \\
\hline م 1.2 & إرتفاع المصدر \\
\hline 0.62 & فرق المسار : أ+ب-ج \\
\hline 20 & قيمة التو هين الصوتى (IL) عثد تردد 1000 هرتز \\
\hline 68 ديسيبل & مستوى شدة الضوضاء الخارجية عند المستقبل \\
\hline 68-68= 48ديسييل & مستوى شدة الضوضاء مع وجود حاجز \\
\hline
\end{tabular}

• مقترحات على المستوى التصديمي :-

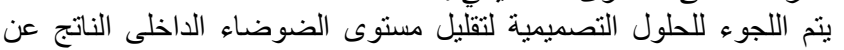

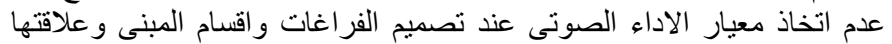

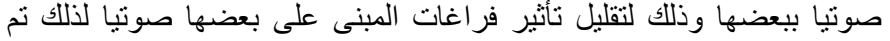

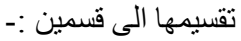

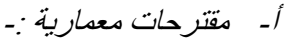

• استخدام حو اجز صوتية (Buffer Zones) من الفر اغات الاقل حساسية

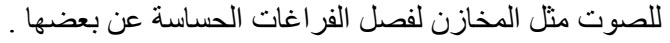

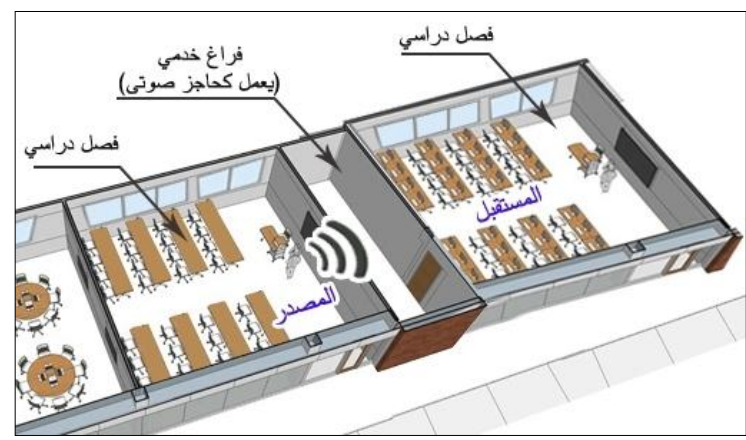

شكل. 19. استخدام حواجز من فراغات غير حساسة مثل المخازن بين الفراغات الإر اسية غير

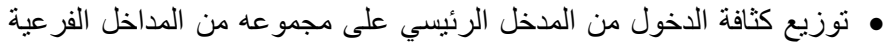

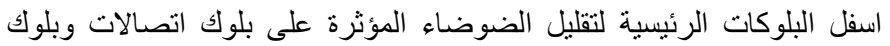




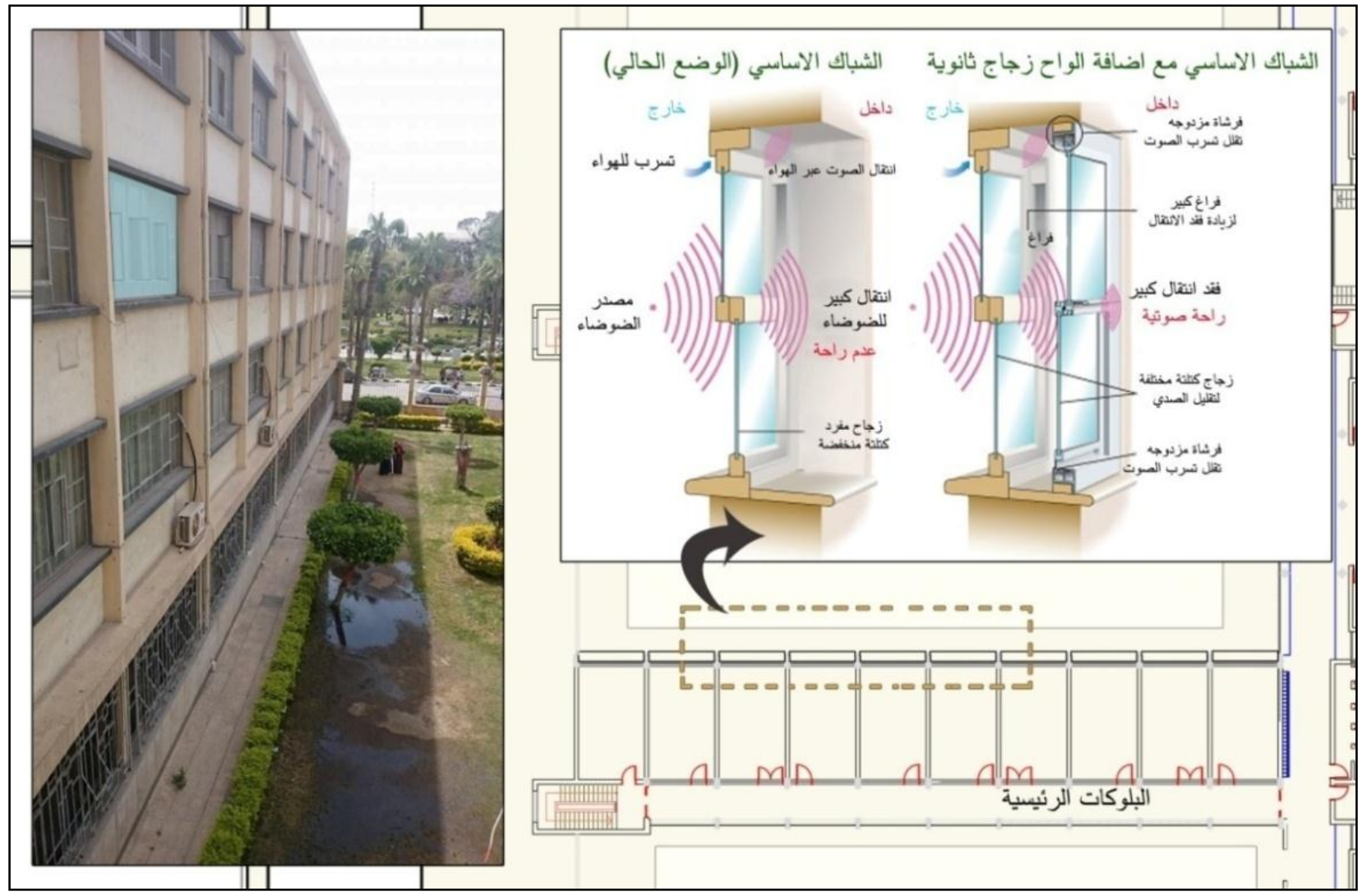

شكل. 22. الفرق بين الثبابيك الحالية والثبابيك المزدوجه لفقد انتقال الصوت خلالها

ج- استخدام الحواجز الصوتية.

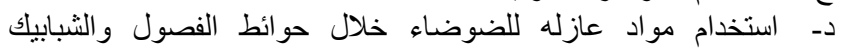

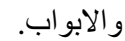

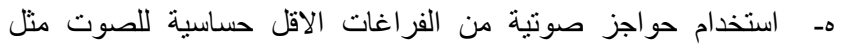

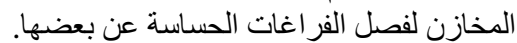
و - توزيع كثافة الاخول من المدخل الرئيسي للمداخل الفئل الفر عية.

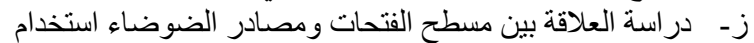
كاسر ات وحواجز صوتية بالو اجهات .

\section{النتائسج}

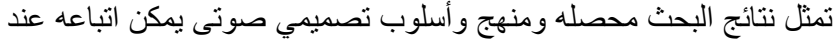
تصميم المبانى التعليمية الجديدة ويمكن ايجاز هذه النتائج في النقاط التهي التالية:

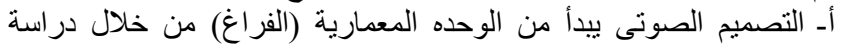
المؤثرات الصوتية عليها ( مؤثرات خارجية وداخلية ) ووسائل التحكم بها لأنها وتفاديها خلال مر احل التصميم الاولية.

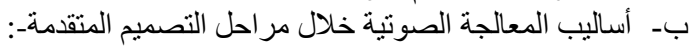

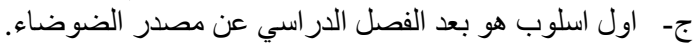

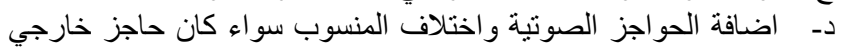

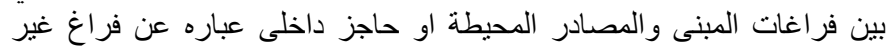

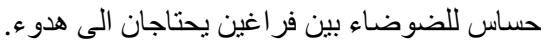

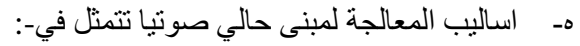
و - در اسة العلاقة بين فراغات المبنى والمصادر المحيطة والمئن وامكانية التغيير

\section{VI}

تناول البحث وسائل التحكم فى الضوضاء عند المصدر والمستقبل و الثناء

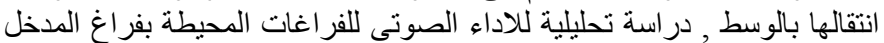

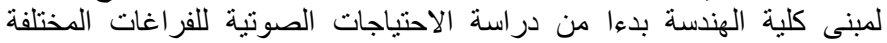

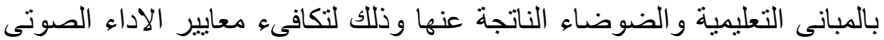

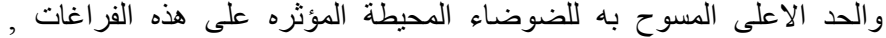

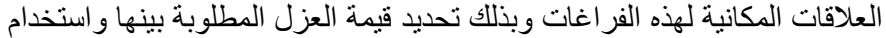
جهاز قياس مستوى شدة الضوضاء

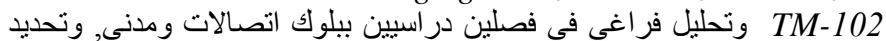

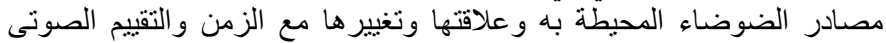

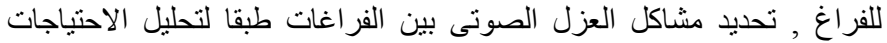

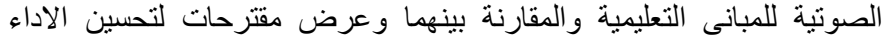

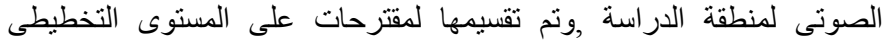
و التصميمي .

\section{نتائج الدراسة التطبيقية لمنطقة الدراسة بالفراغات المحيطة $\quad$ VII

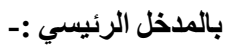

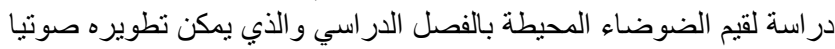

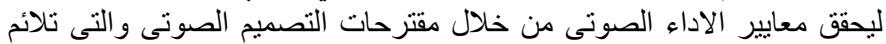

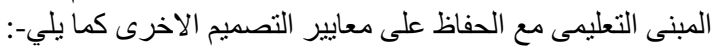

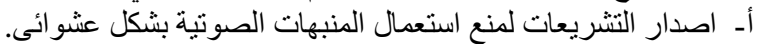

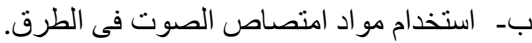




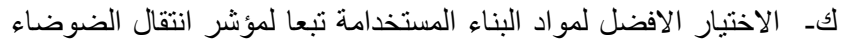

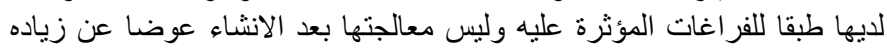

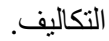

لـ - مر اعاه الاحتياجات الانسانية للمبانى المختلفة طبقا لنوع النشاط والذى الإنى

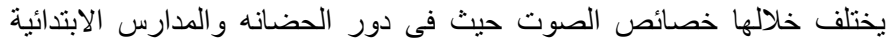

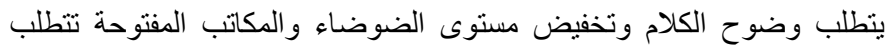
الحد من انتشار الصوحت اما المستشفيات فتتطلب التقليل من مستوى الصوت الصوت وهو الأمر الأكثر أهمية . النمار الهبو

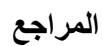

[1] Acoustical Society of America "American National Standard Acoustical Performance Criteria, Design Requirements, and Guidelines for Schools", ANSI/ASA S2009-12.60/PART 2, P6, 2009.

[2] Acoustic Treatment - one (Noise and Vibration Control) MEBS 6008, Publish- Modified 2006

[3] Zuhair,"Measurement of Noise Level Coming from Electric Generators in Karbala University", International Journal of Computer Science and Electronics Engineering (IJCSEE) Volume (3), Issue (3), P (2), 2015.

[4] Building Bulletin 93, Acoustic Design of schools, A Design Guide, p9, London, 2013.

[5] B. David," Jagged-edge Noise Barriers" Department of Mechanical Engineering, The University of Texas at Austin, 1998.

[6] Environmental Protection Department, the Government of the Hong Kong Special Administrative Region," Environmental Noise", 2005.

[7] [أحمد الخطيب , "الصوتيات الدعمارية (النظرية والتطبيق )" , 2003.

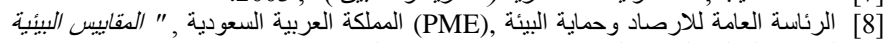

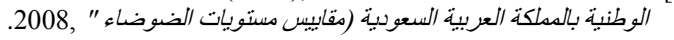

[9] سعود صادق حسن , "الاضاءة والصوتيات فى العمارة", كلية العمارة و التخطيط , جامعة الملك

[10] مجلس وزاره الاسكان و التعمير العرب ,الكودات العربية العوحده لتصميم وتنفيذ العبانى, كود

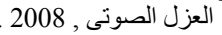

[11]وزارة الإسكان والمر افق و المجتمعات العمر انية ," الكود المصرى لأسس تصميم وشروط تنفيذ أعمال الصوتيات و التحكم في الضوضاء للمبانى ", 2011.
المكاني لها لتقليل مستوى شدة الضوضاء بالفر اغات الحساسه للضوضاء الضاء.

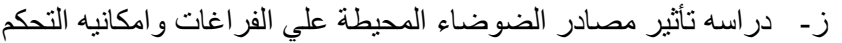

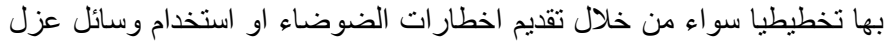

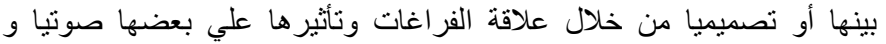

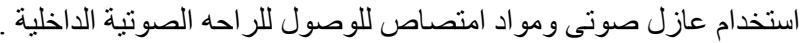

\section{التوصيات}

أ_قبل مرحله التصميم المبدئية يجب عمل وصف للضوضاء البيئية المحيطة بموقع اقامة المبنى التعليمى. التهيم.

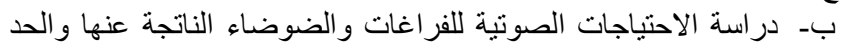

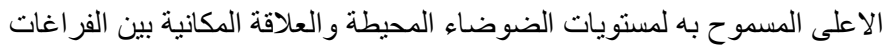
المختلفة.

ج- لابد من تكامل العناصر البيئية والصوتية وعدم تأثير التصميم الصوتى الإدى

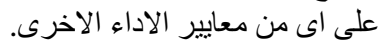

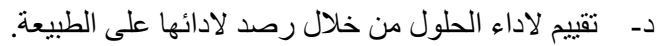

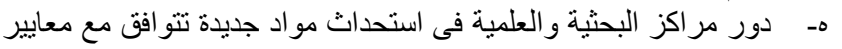

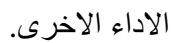
و - استخدام انظمه التقوية الصناعية عند الضرورة لتحقيق قيمة مثلي عند أذن المستمع تساوى حو الى 75 ديسييل.

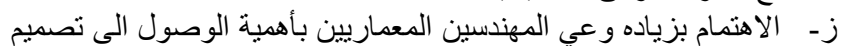

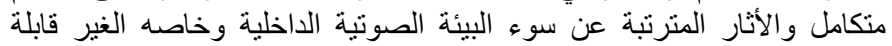
للتحسين صوتبا لاحقا.

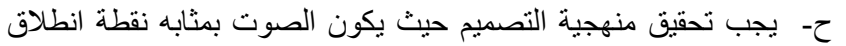

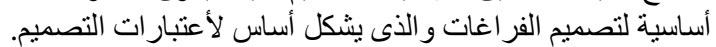

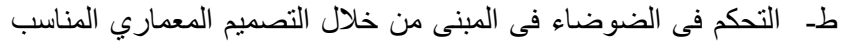

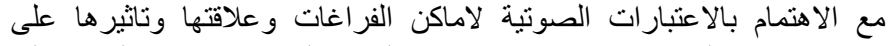

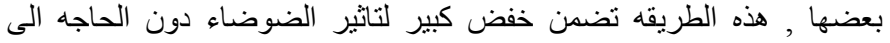

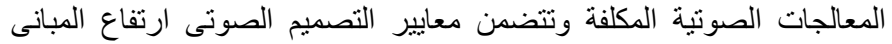

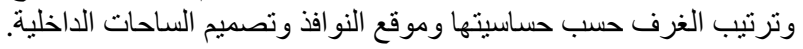

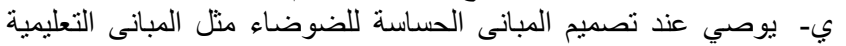

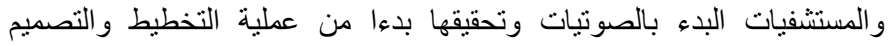

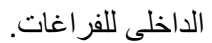

